\title{
Feminization of Agatha Christie's Character Hercule Poirot through His Appearance, Personality, Age and Cat Symbolism
}

\section{Mária Lujza Csorba}

\begin{abstract}
This article aims to analyze how Agatha Christie's character Hercule Poirot is feminized through several aspects, namely his appearance and character, his age and recurring cat symbolism. All the aspects and their examples were collected from Agatha Christie's Hercule Poirot stories employing close reading as a method. By the use of several academic papers focused mainly on the topic of gender stereotypes in connection to the presented examples from Agatha Christie's works, the central argument is that the character of the male detective Hercule Poirot is strongly feminized. Although this theory is already widely accepted, this article focuses on its less frequently discussed aspects, namely cat symbolism and age-related feminization.
\end{abstract}

\section{Keywords}

Agatha Christie, Hercule Poirot, Detective Fiction, Feminisation, Symbolism 


\title{
Feminization of Agatha Christie's Character Hercule Poirot through His Appearance, Personality, Age and Cat Symbolism
}

\author{
Mária Lujza Csorba
}

\section{Different Aspects of Hercule Poirot's Feminization}

Every Agatha Christie's novel from the Poirot Series contains a description of Hercule Poirot's physical appearance, his qualities, personal preferences, habits and age. In some books, these descriptions are more detailed than in others, however, they appear numerous times in each of the stories. Other characters often discuss his looks and behaviour, sometimes in a way of admiration, sometimes to ridicule him. The frequency of such situations shows how important his overall looks and character are for the stories.

\section{Hercule Poirot's Physical Appearance and Its Feminization}

Poirot's most well-known features, originally introduced in the first novel from the Poirot series - The Mysterious Affair at Styles (1920), are his height, egg-shaped head, and most importantly, his incredible black hair and moustache. All these characteristic properties are mentioned in the first introduction of Poirot's character, as his good friend Captain Arthur Hastings describes him: "He was hardly more than five feet four inches, $[\ldots][\mathrm{h}]$ is head was exactly the shape of an egg, [...] [h] is moustache was very stiff and military" (MAS, 23). Because of its unconventionality and originality, Poirot's appearance draws attention and is unforgettable, as it is also clearly stated in the stories. In Christie's After the Funeral (1953), a certain inspector, while smiling, pointed out to Poirot that it "wasn't difficult" to recognize him after many years, since "[his] appearance is - rather unusual", and added that Poirot "stick[s] out in a country place" (AF, 166).

Hercule Poirot is most often referred to by attributes such as "little", "funny", "ridiculous", "extraordinary", "quaint", "strange", etc. which are used directly in relation to his appearance. Usually, when other characters refer to him, they use variations of statements such as "[...] the extraordinary little man" (MAS, 96), "He's a dear little man", “[...]this quaint dandified little man...” (MAS, 23), "A ridiculous-looking little 
man" (MOE, 6), "[...]that funny little man[...]" (MRA, 74), "The strange little man[...]" (MRA, 19) etc. It is evident that the attribute "little" is used most frequently, although sometimes replaced by the word "small" while describing his figure - "[...]his small neat person..." (LH, 3), "[...]a small compact figure[...]" (LH, 7).

According to Ye. Yu. Bereznykh, the words "small" and "little" are interchangeable, with a minute difference in meaning. Bereznykh defines the word little as "more absolute in implication often carrying the idea of petiteness, [or] insignificance" (77). From a gender-stereotypical point of view, it is more common for women to be described by such attributes than men, since men usually find it offensive and hurtful to their masculinity. This fact is demonstrated, for example, on the Internet and its online forums focused on English language, where questions such as "Is there a more masculine way to describe a 'petite' man?" ("Is there a more masculine...") occur with rich discussions underneath them. The evidence of Poirot's descriptive feminization is also settled by Erin Davis, the author of the visual essay The Physical Traits That Define Men \& Women in Literature, who after analysing 2000 literary works published between the years 1008 and 2020, stated that in literature, both the words "small" and "little" are almost two-times more likely to be used in the description of a woman's body than a man's (Davis).

The most memorable and famous feature of Hercule Poirot is undoubtedly his flamboyant black moustache, which is simultaneously admired and made fun of by the people around him. He himself considers his moustache to be his pride and absolutely cherishes it, as is stated in one of the stories - "His moustaches had always been his sensitive point. He was extraordinarily proud of them" (ABCM, 3). Usually, this pride of Poirot meets with attributes such as "incredible", "great", "luxurious" or "famous" and the consensus is that it is unmistakable. He is often recognized only by the moustache and, therefore, referred to as, for example, "the luxuriantly moustached stranger" (LH, 179), "Little chap [...] big moustaches" (TG, 143), "a little man with enormous moustaches" (MOE, 6), or a man with "an incredible moustache!” (FLP, 82) etc. Characters prove it during several occasions, as for example when Miss Norma Restarick in Third Girl (1996) answered Poirot's question "What made you recognize me?" with words "Your moustache, [i]t couldn't be anyone else" (TG, 88), or, as in the same novel, Poirot's old friend Mrs. Oliver noted that "[n]obody could mistake those moustaches" (TG, 139). The author often emphasizes this feeling of fascination by simply directing to the thought process of another character, outside the dialogue, as for example in the book Cards on the Table (1936) - "[she was] secretly studying the amazing moustache of [Hercule Poirot]" (CT, 241), or in Third Girl (1966) - "Her eyes rested on his moustaches with a kind of fascination" (TG, 32).

In later works, Captain Arthur Hastings gradually reveals that his good friend Poirot's notorious black hair and moustache are products of hair dye ${ }^{1}$, which eventually

\footnotetext{
${ }^{1}$ In the book The ABC Murders (1936), Captain Arthur Hastings, after not seeing Poirot for a long time, notices something strange and says to Poirot - "In fact, if it were possible, I should say that you had fewer grey hairs than when I saw you last" (ABCM, 3), only to learn afterwards that it is true. Poirot's revelation is followed by Captain's cry - "Poirot, you have dyed your hair!" shouted in disbelief. The reaction of Captain Hastings supports the fact that such conduct is not perceived as very masculine.
} 
result in a wig and a false moustache in his later years, both kept in secret until his death. Poirot made a confession in the last letter addressed to Captain Hastings, writing - "You may not have realized it, but I wear a wig, Hastings. You will realize even less that I wear a false moustache" (CPLC, 235). On one occasion, a recurring character of Chief Inspector Japp describes Poirot as "[q]uite a good advertisement for a hair tonic" (ABCM, 11). Firstly, after revealing his big secret about using hair dye, Poirot suggests that Captain Hastings could also help looking "a little bit thin on the top" (ABCM, 10) by a "little device" from his hairdresser which is "not a wig" (ABCM, 12). Captain Hastings, whose masculinity and self-esteem is endangered by this suggestion, roars "Once and for all I will have nothing to do with the beastly inventions of your confounded hairdresser" (ABCM, 13). Captain Hasting's reactions to the subject of improving one's - man's - hair condition prove that such conduct is not regarded as common, and he does not support it. This fact also supports the theory of Poirot's feminization, since stereotypically, women are known to put much greater effort into their appearance than men, especially regarding hair. The evidence is provided by a study on body dissatisfaction, which proves that "women [are] significantly more dissatisfied with their bodies than men" (Quittkat et al. 6-7) and "women indeed place more importance on their appearance compared to men" (Quittkat et al., 8). Again, the work of Erin Davis also proves this argument, since the results of her research clearly show a significant difference between men and women in this area. The term "dye" in connection to hair is eight-times more likely to be used in literature while describing a woman's hair than a man's hair (Davis). The subject of hair dye will be discussed further in Section 1.3.

Finally, the last relevant aspect of Hercule Poirot's appearance is represented by his clothing. Poirot's long-term employee named George describes him as "[v]ery particular about his clothes" (CPLC, 209). His clothes - and overall appearance - must always be neat and clean. Even while searching for evidence, "Hercule Poirot does not run the risk of disarranging his costume without being sure of attaining his object" (MRA, 114). Once he makes such sacrifice ${ }^{2}$, although helpful and needed, disarranging of his clothes bothers him greatly, as observed in one of the books - "[Poirot] began to fuss about a few microscopic drops of water on his coat sleeve" (MRA, 114). On a few occasions, he is even described as "immaculately dressed" (LH, 143), which is sometimes met, just like other aspects of his appearance and character, with ridicule. However, Poirot seems to be unconcerned with unpleasant remarks made by other people, usually not responding at all, or, on one occasion, nonchalantly saying "I am flattered. One hopes to present a good appearance" ( $\mathrm{LH}, 143)^{3}$. Poirot also often considers clothing choices of other people, which is observed by his friend Captain Hastings who calls Poirot a "man milliner", adding that unlike Poirot, he himself "never

\footnotetext{
${ }^{2}$ In the Murder of Roger Ackroyd (1926), Poirot is forced to retrieve an object - possible evidence - from a muddy pond. While doing it, he stains the sleeve of his coat and it makes him very displeased.

${ }^{3}$ In the Labours of Hercules (1947), after entering a room, Poirot's clothing, containing "a white camelia in his buttonhole" (LH, 143), is regarded with a sarcastic remark from the person sitting behind a desk "On your way to the Royal Enclosure at Ascot? No? My mistake" (LH, 143).
} 
notice[s] what people have on" (ABCM, 148).

Hercule Poirot is known for "always wearing patent leather shoes" (LH, 234) which are his favourite, however, they are not very useful in terms of functionality. Throughout the stories, it is mentioned numerous times that his feet ache from wearing them - "...he sat down on the stone bench there, to rest his feet which were, as was his custom, enclosed in tight, pointed patent-leather shoes" (DMF, 159). He refuses to take them off even in extreme conditions, as for example, when his car broke down in the middle of winter on a snowy road, and "Hercule Poirot, wearing his usual smart patent leather shoes, had been forced to walk [...] mile and a half to reach the riverside village..." $(\mathrm{LH}, 79)$ which almost caused his feet to freeze.

The fact that throughout the books, Poirot's preference for his patent leather shoes and his need for a neat and clean attire are oftentimes highlighted only later to comment on their poor functionality, directly refers to the strong feminization of his character. A study aimed at the function of clothes carried out through gender analysis proves, that men, in comparison to women, put much more stress on the "functional benefits" (Cox and Dittmar 237) of their clothes as well as that "men ha[ve] a more functional, instrumental, and activity-related focus" (Cox and Dittmar 240) towards clothing, which - as discussed in the previous paragraph - does not correspond with Poirot's preferences in regard to clothing. The study states that according to its results, women "[show] more concern about the role of their clothes in social interrelations with others" (Cox and Dittmar 254) than men, and also that "the proposition that clothes may have greater self-definitional importance for women than for men was supported" (Cox and Dittmar 258). Referring to the evidence of Poirot's point of view on matters regarding appearance and choices of clothing, the study of Cox and Dittmar prove that such attitude is clearly more feminine than masculine.

Furthermore, the obviously non-masculine way of presenting Poirot's footwear choices seem to heavily refer to the style of shoes typically wore by women - high heels. This kind of footwear, similarly to Poirot's favourite pair of shoes, is often described as uncomfortable, hard to walk in and even dangerous due to possible health impacts or injuries. The front pointed part - which both high heels and Poirot's pointed leather shoes have in common - is usually the cause of discomfort and possible foot disability (Bruck and Lambert 1580). Although the discomfort while wearing such shoes - high heels or Poirot's pointed patent leather shoes - is evident, as well as the health risk of it, both parties - women and Hercule Poirot - seem to rather focus on the appearance and its effect than on comfort and functionality.

\section{Hercule Poirot's Personality and Its Feminization}

Similarly, to Hercule Poirot's appearance, which is often described as unconventional and even strange, the same can be said about his nature, character and qualities. He is a very neat person, both mentally and physically. The most used words from his vocabulary are "order" and "method", which are of utmost importance in his life, as he himself explains - "it is my habit to be neat and orderly" (MOE, 111). This 
crucial aspect of his personality is very well known to other characters surrounding him, as in one of the stories, a character of Mr. Franklin, who was not in any way close to Poirot, says with certainty: "He's got a methodical mind" (CPLC, 175). It is even blatantly pointed out by his friend Arthur Hastings, when he once says to Hercule Poirot, regarding the topic of his orderliness and constant need of a method of some sort: "It's almost a disease with you" (ABCM, 247). Although Poirot, lacking objectivity, does not agree with his friend's opinion, he admits that he sometimes "may be overstressing" (ABCM, 247) certain points. The matter of neatness is so strong and important for Poirot, that there is no need for him to pay any attention to the process of straightening, arranging or putting things to order, as Captain Hastings commented one time that due to "long force of habit", Poirot's hands were "mechanically straightening the spill vases on the mantelpiece" (MAS, 84). A similar situation was observed and described by the narrator of The Murder of Roger Ackroyd (1926), when he noticed that Poirot's significantly neat way of putting away evidence was "purely mechanical" (MRA, 224).

This concept of tidiness is prevalently visible also in Poirot's surroundings, as his numerous abodes throughout the books are always described in a very similar fashion. In the Murder of Roger Ackroyd (1926), the narrator perceived Poirot's "little sitting-room arranged with formal precision" (MRA, 78). At the beginning of The ABC Murders (1936) when Captain Hastings comes to visit his dear friend Poirot to his new home, he describes their encounter like this: "I accused him (and he admitted the fact) of having chosen this building entirely on account of its strictly geometrical appearance and proportions", followed by Poirot's question “... it is of a most pleasing symmetry, do you not find it so?" (ABCM, 1). He also later notes, when Poirot is taking a letter from the drawer of his table, that "[the table's] contents, I need hardly say, were all neatly docketed and pigeon-holed so that he was able at once to lay his hand upon the paper he wanted" (ABCM, 5). The aspect of symmetry is of utmost importance regarding Poirot's home, as it was described in The Labours of Hercules (1947) - "A square room, with good square modern furniture - even a piece of good modern sculpture representing one cube placed on another cube and above it a geometrical arrangement of copper wire" (LH, 7). This obsession with symmetry is clearly stated in the narration of Five Little Pigs (1943), when Poirot cannot bear to not ask one question of each of the five people surrounding him, although he only needs four answers - “...it was really only his insatiable passion for symmetry that was bringing him here. Five people - there should be five questions! It was neater so. It rounded the thing better" (FLP, 247).

The aspects of Poirot's character introduced in the previous two paragraphs confirm the presence of feminization in Poirot's characterisation. Cleanliness and tidiness are features traditionally and stereotypically connected to women rather than men. A research conducted on gender equality in the cleaning industry in Norway clearly states, that "women were seen as better suited for cleaning," because of "their innate 'tidiness', the ability to see and act on mess and untidiness" (Orupabo and Nadim 8). The study also provides quotes from several employers from the researched sector, with one of them stating - "I see that the woman is tidier. [...] I have some girls, and they're tidier than the boys..." (Orupabo and Nadim 8). Similarly, a study published in the 
Mária Csorba, Feminization of Agatha Christie's Character Hercule Poirot through His Appearance, Personality, Age and Cat Symbolism

International Journal of Research in Marketing focused on gender representation in advertising - particularly advertisements of cleaning products - proves that cleaning has been for many years regarded as a woman's job, while stating that an attempt for a change of this perception "comes after very many years of heavy media expenditure [...] which have consistently portrayed the [cleaning] products as being used only by women" (Elliott et al., 313). Women participating in the experiment presented in the study, after watching several advertisements on cleaning products, agreed, that such ads convey a message that "women know best about cleaning" and that "women do more housework than men because they are better at it, they know how to do it and what to use" (Elliott et al., 317-318). Such results testify the wide perception of matters such as cleanliness and tidiness being connected mainly with women. The presented examples also clearly show that a man characterized as "neat", "tidy" and "clean" is profoundly feminized.

\section{Feminization of Hercule Poirot's Character through His Age}

In the books, it is explicitly communicated numerous times that Hercule Poirot is overly sensitive regarding his old age, as for example in Dead Man's Folly (1956), Christie writes - "Poirot himself was always reticent on the subject of his age" (DMF, 225). One of the stories is actually founded on the matter, when in the beginning, a client - a young girl - refuses to accept his services due to his advanced age, telling him "You're too old. Nobody told me you were so old" (TG, 6) and he is not able to deal with such insult. Afterwards, he confides in his good friend, Mrs. Oliver, by saying "It wounded me" (TG, 11), as well as on a different occasion, about the young girl's hurtful remark, he admits - "I was in distress. Something extremely painful had been said to me" (TG, 163). Similar situation occurs at the beginning of Five Little Pigs (1943), when Poirot must convince a potential client that he is "the best" while she is visibly doubting his abilities because he is "older than [she] imagined" (FLP, 2). Such statements and remarks aimed at Poirot's obviously advanced age are present throughout all books, usually connected to lack of respect from other characters and expectations that due to being old, he is not capable of doing his job properly anymore. Although his reputation of being a great detective often precedes him, comments aimed at his age, such as "I expect he has been quite good in his day. He's gaga now, of course. He must be at least sixty. [...] let's go and see the old boy" (CT, 196), "Maybe he was a little Belgian wizard in his day - but surely, man, his day's over. He's what age?" (DMF, 225) and "Mr Poirot's done some good stuff in his time, but I think he is a bit gaga now, sir" (ABCM, 172) are very common. One time, he was even expected to be already dead by a character who knew him many years ago, who after being asked "You know of [Hercule Poirot]?" answers - "Yes. [...] but I imagined that he was dead long ago," following with the statement "he could hardly be young" (AF, 110). Based on the presented examples, the subject of Poirot's age is significant for the stories and it is also discussed often.

As it was previously stated, Poirot used to hide his advanced age by employing a black hair dye to cover his grey hair. He was successful in it for a significant period, 
since not even his best friend Captain Hastings was able to reveal his secret, commenting once - "[Poirot] was looking wonderfully well - hardly a day older than when I had last seen him" (ABCM, 2) ${ }^{4}$. However, Poirot continues with this habit until the very end, as in the last book of the Poirot series, Curtain: Poirot's Last Case (1975), Captain Hastings remarks that "[t]here comes a moment when hair dye is too painfully obvious," but he "would not for the world have hurt [Poirot's] feelings by saying so to him" (CPLC, 11). Only later, after Poirot's death does Captain Hastings find out that because "M. Poirot's hair came out a good deal lately" (CPLC, 210), he had to stop dying his hair and start wearing a black wig instead - not only to cover grey hair, but to cover the significant loss of his hair and therefore, his old age. Captain Hasting is aware of Poirot's sensitivity regarding this subject, as in the ABC Murders (1936), he reacts to the Chief Inspector Japp's comments about Poirot being so good as to, eventually, be "detecting [his] own death" (ABCM, 11) by an inner monologue - "Poirot, poor old chap, is getting on. Jokes about his approaching demise can hardly be agreeable to him" (ABCM, 11).

Poirot's feminization can be detected from the previously described perception of his character through his old age, since according to researchers, "there is a 'structural congruence of physical appearance and old age stereotypes'" however, the research states that, mostly, "the physical appearance of middle-aged and older women" is judged "more harshly than that of their male counterparts" (Pliner et al. 264). The presented evidence proves that several aspects of Poirot's physical appearance, mainly those influenced by old age, such as his dyed hair, are often judged and discussed in an impolite manner. Julie Winterich's study on aging in women also supports this matter, by stating that "aging women deal with greater stigmatization of their appearances than do aging men" (Winterich 54), and according to the study's results, one of the three main aspects of aging that women deal with are grey hair. These aspects were explained by using only negative connotations, as women studied by Winterich stated that "once their grey hair became visible, younger people [started to treat] them disrespectfully" (Winterich 62). Regarding the topic of grey hair, one of the women mentioned noticeable "discrimination" while comparing women and "young people and men", and that women's decision to cover their grey hair stems from their need "to receive respectful treatment" (Winterich 63). A study on aging and fears connected to it published by Brunton and Scott also supports the argument about a certain kind of discrimination between men and women, stating that "a double standard of ageing exists for both men and women," adding that "[f]or women it exists in regards to an ageing appearance" (Brunton and Scott 8) and that "aging anxiety [...] strongly correlated with the extent women focus on their looks" (Brunton and Scott, 9). The evidence from previous paragraph clearly shows that Poirot suffers the same kind of treatment in the form of lack of respect due to his visible old age, therefore he is inclined to focus on his looks and improve his appearance in typically feminine ways.

In connection to Poirot's strong sensitivity regarding the subject of his age, Brunton and Scott's study proves that "men and women have different fears of aging"

\footnotetext{
${ }^{4}$ This thought occurred to Captain Hastings only a moment before he learned the truth about the black hair dye - the sequence already described in a previous chapter.
} 
(Brunton and Scott 1) connected to "age-related changes" which, for men, "are generally in areas of functioning (memory/health)" and in areas of "appearance" (Brunton and Scott, 8) for women. This fact, along with a few examples from the books, provides the evidence that in this area, Poirot really does relate more to women than to men. In the last book - Curtain: Poirot's Last Case (1975) - Captain Hastings, before providing a description of Poirot's physical condition ${ }^{5}$ begins with a remark - "Nothing is so sad [...] as the devastation wrought by age" (CPLC 11). However, in the same book and on several occasions, Poirot emphasizes his ultimate conviction that although "[his] limbs, they are no longer active, [... his] brain [...] is unimpaired" (CPLC 16). After Captain Hastings' numerous remarks about the pity of Poirot not being at his best health, "Hercule Poirot immediately flew into rage", shouting that "there is no need of physical effort" and "one needs only - to think" adding that he "can do it superlatively. My limbs they are paralyzed, my heart, it plays me the tricks, but my brain, Hastings, my brain it functions without impairment of any kind. It is still of the first excellence my brain" (CPLC, 172). By such statements, Hercule Poirot declares that he is confident and sure of himself in relation to the brilliance of his brain and its functioning, and therefore denying altogether any doubts about the fear of "age-related changes [...] in areas of functioning" (Brunton and Scott 8) which is common for aging men. Due to all the evidence proving that Poirot's only concerns related to aging are connected to his appearance, the feminization of his character is fairly apparent, since "body dissatisfaction [is] higher in women than in men" (Quittkat et al. 1). Furthermore, a study on body dissatisfaction comparing the perception of men and women proved, that "only in men did age predict a lower level of the importance of appearance" (Quittkat et al., 1) which serves as the opposite of what is known about the character of Hercule Poirot, who is an old man with an intense focus directed to his physical appearance.

\section{Hercule Poirot's Feminization through Cat Symbolism}

Several times throughout the stories, Hercule Poirot is compared to a cat either by the author, or by other characters in the books. Usually, this comparison stems from Poirot's habits, behaviour or his green eyes - "The man reminded me in some ways of a cat. His green eyes and finicking habits" (MRA 114). The same reference to his eyes occurs in other stories - "His eyes opened. They were green like a cat's" (MOE, 218), "[t]here was a strange, cat-like gleam in his eyes" (CT 235). The symbolism is present since the first Poirot story, The Mysterious Affair at Styles (1920), in which Captain Hastings remarks that he "often before noticed that, if anything exited [Poirot], his eyes turned green like a cat's" (MAS 88). The recurring reference to Poirot's cat-like eyes in relation to his excitement regarding his detective work correlates with a notion of cats' ability to cast "a spell on their prey" (Hannah 22) by using their eyes - "A bird, for instance, is sometimes totally unable to fly away if it is caught in the spell of a cat's

\footnotetext{
5 The full description of Poirot's appearance from this sequence:

Crippled with arthritis, he propelled himself about in a wheeled chair. His once plump frame had fallen in. He was a thin little man now. His face was lined and wrinkled. [...] Only his eyes were the same as ever, shrewd and twinkling, and now - yes, undoubtedly - softened with emotion" (CPLC, 1975, 11).
} 
eyes" (Hannah 22).

Most often, characters notice the similarity while Poirot is in one of his elements - he is either psychologically toying with a suspect or a witness, or he is on the verge of revealing ground-breaking information, both of which provide him much pleasure. The former situation occurs in Murder on the Orient Express (1934), when Poirot interviews one of the suspects. The author notes, that he looks "like a cat pouncing on a mouse" (MOE, 154). Similarly, in Third Girl (1966), Chief Inspector Neele compares Poirot and his working habits to "a good mouser. A cat sitting over a hole waiting for a mouse to come out" (TG, 189). Based on these descriptions of Poirot, calling him names such as $a$ good mouser, a clear correlation between his character and cats as "cruel and crafty hunters who will play with their living prey before eating" (Hannah, 22) can be observed. Poirot, regarding his technique, is also known for not making rash decisions, but rather waiting for the right moment to do something, which is also addressed in the manner of a cat simile - "Hercule Poirot leant back in his chair, sipped his coffee and observed, as a cat may observe the twittering and comings and goings of a flock of birds. The cat is not ready yet to make its spring" (AF 225). This description suits the principal definition of a cats' hunting process - "[Cats] wait motionlessly for their prey to draw closer and then approach silently to catch them" (Park 45). The latter situation is described in Dead Man's Folly (1956), when immediately before revealing the name of the killer, Poirot's smile is presented as "the contended smile of a cat who has lapped up a saucer of cream" (DMF 229). Another time, "[Poirot's] voice purred, soft and cat-like" (CT 248) while again, revealing the name of the murderer. On one occasion, when Poirot is receiving a compliment from an old friend, Countess Vera Rossakoff, his satisfaction is also compared to purring of a cat - "If Hercule Poirot had been a cat he would have purred" (LH 360).

In terms of symbolism, cat is called "a symbol of the feminine," which "contains positive aspects like the spiritual instinct, fertility, richness and healing" (Park 43). General consensus, as well as evidence gathered from academic sources, prove that symbolically, cats as animals are connected rather to women than men, since "in several cultures, cats are linked with women and goddesses including Bast/Bastet (Egyptian), Artemis/Diana (Greco-Roman), and Freya (Scandinavian)" (Werness 73). Based on this women-cats connection various superstitions came into existence, referring, for example, to witches and cats being their "demonic familiars", or even "the Devil incarnate" (Werness 73). Another source confirms this fact, stating that "cats are [also] associated with negative femininity such as shrewdness, betrayal, cruelty, and witches" (Park, 44). Moreover, various expressions describing women's behaviour also originate from the feline connection, such as "'catty', 'cat fight' and 'like a cat in heat"” (Werness 73).

In the book Archetypal Symbolism of Animals (2006), the author Barbara Hannah states that although the "cat's archetypal image is present in us all[, i]t is clearer to women, for the cat - even the tomcat - is much more feminine in behaviour than, for instance, the dog" (Hannah 51). Ae-kyu Park, the author of the article The Cat: A Symbol of Femininity, states that when using the symbol of a cat about a man, it is only done by the term "anima", which is "the unconscious feminine in men" (43), so it still, in a 
certain way, represents the idea of femininity rather than masculinity. The article describes cats as "elegant, haughty, and refined" and having "a mystical femininity" (Park 44) which, based on the provided descriptions from Poirot stories and previous findings, are all attributes that could be used also to describe the character of Hercule Poirot.

\section{Concluding Remarks}

On the basis of the analysis conducted in this article, the argument is that Agatha Christie's character, detective Hercule Poirot, is strongly feminized. This feminization stems from a number of aspects introduced by Agatha Christie, namely Hercule Poirot's appearance and personality, his age and the symbolism of a cat frequently associated with him. The argument is supported by the textual evidence collected from Poirot novels along with additional academic works focused on the presented issue. The examples drawn from the different works validate the argument.

\section{List of Abbreviations}

$\begin{array}{ll}\text { ABCM } & \text { The ABC Murders } \\ \text { AF } & \text { After the Funeral } \\ \text { CPLC } & \text { Curtain: Poirot's Last Case } \\ \text { CT } & \text { Cards on the Table } \\ \text { DMF } & \text { Dead Man's Folly } \\ \text { FLP } & \text { Five Little Pigs } \\ \text { LH } & \text { The Labours of Hercules } \\ \text { MAS } & \text { The Mysterious Affair at Styles } \\ \text { MOE } & \text { Murder on the Orient Express } \\ \text { MRA } & \text { The Murder of Roger Ackroyd } \\ \text { TG } & \text { Third Girl }\end{array}$




\section{Works Cited}

Berezhnykh, Ye.Yu. "How to Select Adjectives." Philology. no. 6, 2016, pp. 77.

Bruck, H.O., and Lambert, C. N. "Common Foot Disabilities." The American Journal of Nursing. Vol.59, no.11, 1959, pp. 1580-1583. https://doi.org/10.2307/3417913

Brunton, R. J., and Scott, G. "Do We Fear Aging? A Multidimensional Approach to

Aging Anxiety." Educational Gerontology. Vol.41, no.11, 2015, 786-799. https://doi.org/10.1080/03601277.2015.1050870

Christie, A. The Mysterious Affair at Styles. $12^{\text {th }}$ edn. London: HarperCollins Publishers, 1920

Christie, A. The Murder of Roger Ackroyd. $5^{\text {th }}$ edn. London: HarperCollins Publishers, 1926

Christie, A. Murder on the Orient Express. $7^{\text {th }}$ edn. London: HarperCollins Publishers, 1934

Christie, A. The ABC Murders. $4^{\text {th }}$ edn. London: HarperCollins Publishers, 1936

Christie, A. Cards on the Table. $12^{\text {th }}$ edn. London: HarperCollins Publishers, 1936

Christie, A. Five Little Pigs. 14 ${ }^{\text {th }}$ edn. London: HarperCollins Publishers, 1943

Christie, A. The Labours of Hercules. $11^{\text {th }}$ edn. London: HarperCollins Publishers, 1947

Christie, A. After the Funeral. 10 ${ }^{\text {th }}$ edn. London: HarperCollins Publishers, 1953

Christie, A. Dead Man's Folly. 12 $2^{\text {th }}$ edn. London: HarperCollins Publishers, 1956

Christie, A. Third Girl. $7^{\text {th }}$ edn. London: HarperCollins Publishers, 1966

Christie, A. Curtain: Poirot's Last Case. 10 $0^{\text {th }}$ edn. London: HarperCollins Publishers, 1975

Cox, J., Dittmar, H. "The functions of clothes and clothing (dis)satisfaction: A gender analysis among British students." Journal of Consumer Policy, vol.18, no. 3, 1995, pp. 237-265. https://doi.org/10.1007/bf01016513

Davis, E. "The Physical Traits That Define Men \& Women in Literature." The Pudding ${ }^{\circledR}$. New York, 2020, Accessed 21 December $2020 .<$ pudding.cool/2020/07/gendered-descriptions/>

Elliott, R., Eccles, S. and Hodgson, M. "Re-coding gender representations: Women, cleaning products, and advertising's 'New Man'." International Journal of Research in Marketing, vol., 10, no.3, 1993, pp. 311-324. https://doi.org/10.1016/0167-8116(93)90013-O

Hannah, Barbara. The Archetypal Symbolism of Animals. Ascheville: Chiron Publications. ISBN: 978-1-888602-33-3. 2006

"Is there a more masculine way to describe a 'petite' man?" English Language \& Usage. StackExchange, Apr 21, 2017, 2:49 p.m. Accessed Feb 18, 2021. <english.stackexchange.com/questions/385684/is-there-a-more-masculine-waytodescribe-a-petite-man>

Orupabo, J., Nadim, M. "Men doing women's dirty work: Desegregation, immigrants and employer preferences in the cleaning industry in Norway." Gender Work Organ. 2019. pp. 1-15. https://doi.org/doi:10.1111/gwao.12378

Park, Ae-kyu. "The Cat: A Symbol of Femininity." Journal of Symbols \& Sandplay Therapy. Vol.6, no.1, 2015 pp. 43-61. https://doi.org/10.12964/jsst.150003

Pliner, P., Chaiken, S., and Flett, G. L. "Gender Differences in Concern with Body Weight and Physical Appearance Over the Life Span.” Personality and Social Psychology Bulletin. vol.16, no.2, 1990, pp. 263https://doi.org/27310.1177/0146167290162007 
Quittkat, H. L. et al. "Body Dissatisfaction, Importance of Appearance, and Body Appreciation in Men and Women Over the Lifespan." Frontiers in Psychiatry. Vol. 10. 2019, pp.1-12. https://doi.org/10.3389/fpsyt.2019.00864

Werness, H. B. Continuum Encyclopedia of Animal Symbolism in World Art. London: A\&C Black. 2006

Winterich, J. A. "Aging, Femininity, and the Body: What Appearance Changes Mean to Women with Age." Gender Issues, vol. 24, no.3, 2007, pp. 51-69. https://doi.org/10.1007/s12147-007-9045-1

\section{The Authors}

\section{Bc. Mária Lujza Csorba}

Pavol Jozef Šafárik University, Košice, Slovakia.

\section{The Article}

Date sent: 25/08/2021

Date revised: 05/10/2021

Date Accepted: 10/10/2021 